\title{
Stability Analysis of Non-linear controlled PV boost Converter
}

\author{
Santosh B.S.S ${ }^{1^{*}}$, Mohamed Thameem Anasari.M ${ }^{2}$, Kusuma.Gottapu ${ }^{3}$, Kantarao.P $\mathrm{P}^{4}$ \\ Department of Electrical Engineering, Annamalai University and Annamalai Nagar \\ 608002, India ${ }^{\text {. }}$ \\ Department of Electrical Engineering, Annamalai University and Annamalai Nagar \\ 608002, India ${ }^{2}$. \\ Department of Electrical Engineering, SRKREC and Bhimavaram, India ${ }^{3,4}$. \\ *Corresponding Author: gangadharlakshmi555@gmail.com
}

\begin{abstract}
The development of power electronic converters has brought tremendous change in photovoltaic $(P V)$ system. The input voltage of converter is flexible compared to input current but it is more influenced by the nonlinearity in the PV characteristics under different climatic conditions. In this paper the flexible input voltage is controlled by employing cascade control technique in the PV Stand-alone system. First, the input voltage across the capacitor and the current through inductor of the converter are controlled by retaining linear cascade controller, which is liberalized by the $P V$ Characteristics obtained by maximum power point (MPP) by the state space modeling. Finally, the $P V$ System has instability, when the converter is operating at constant current region $(C C R)$ and this problem poses a challenge to control the design. So as to resolve this issue, a non-linear control with Feedback Linearization Control (FBLC) technique is applied to the converter system. The control laws are derived and implemented to the boost converter. The result reflects better performance in the proposed FBLC technique, which is not influenced by PV operating conditions.
\end{abstract}

Keywords: Cascade Control, Feedback Linearization Control, Maximum Power Point, Photovoltaic System

\section{Introduction}

Renewable sources play a prominent role in the present scenario. The most commonly used energy sources are like Solar, Wind, tidal etc. One of the main renewable energy sources is commonly used in power generation is solar energy. It collects energy from nature and is also abundantly available. The solar energy has a lot of benefits specially to reduce the global warming. The photovoltaic systems are growing rapidly due to advantageous of different ambient conditions. In recent years [1]-[2] the power electronic condition equipment is playing a significant role in PV system and they have been introduced modifications in system configurations. Classifications of PV system have become important in understanding the latest development in improving system performance in energy harvesting.

Choosing an equivalent practical model [3] is become more convenient than ideal model due to the number of unknown parameters. In [4], these parameters always depend on weather conditions like Irradiance and Temperature. In the literature [5], the P-V and I-V characteristics of PV system are very important and need to be determined more accurate. A large range of current can produce in the PV module due to the voltage changes [6]-[7], it is depending on climatic fluctuations. Due to the change in climatic conditions the voltage changes logarithmically and whereas the current changes linearly, so in order to track the change in environmental conditions the voltage should remain constant that can be done through MPP. To overcome these situations, a converter is connected between the load and PV panel in order to obtain the MPP. In this context many strategies [8]-[9] of monitoring the MPP of a PV module was developed. The well-known conventional MPPT techniques are Incremental Conductance approach [10]-[11], Perturb \& Observe [12]-[13], 
Fractional method and etc. Furthermore, the $\mathrm{P} \& \mathrm{O}$ method is comprehensively used because it is very simplest MPPT technique.

DC-DC converters are commonly used in electronic circuits and various applications such as power system, automotive, aircraft, medical equipment, renewable energy systems, electric vehicle, etc. In recent papers [14]-[16], a major aspect to the modelling of the converter is the controller design. The commonly used control methods are to control the duty cycles and the DC link voltage. They are frequently used to attain a stabilized voltage from buck-boost converters [17]-[18]. To regulate the DC link voltage by choosing of conventional control methods [19]. However, this method cannot be suitable for large load variations. Therefore, nonlinear control technique is coming into the picture. Furthermost used method to control switching power supplies is Pulse-width Modulation (PWM). The conventional modulation was controlled power electronics circuits. Its model based on averaging and controlled specific condition operates in [20]-[22]. The conventional controllers do not offer a good large-signal operating transient. Generally used classical controlbased designs of conventional controllers require precise linear mathematical models. The conventional controllers failed to perform satisfactorily [23]-[24] uncertainty in parameters, nonlinearity, load disturbance, etc. It can be controlled by means of sliding-mode (SM) control, by using variable structure control system (VSCS). However, there are still a few issues in the converters, which have led to the drift to advanced control strategies like input output linearization [25]-[26], feedback linearization [27]-[28], which are non-linear and does not provide themselves to the application of linear control theory.

In this work, a practical equivalent model of solar cell with series resistance and shunt resistance is considered. Because of the P-V curve characteristics are non-linear; the MPP of a PV can be obtained by using P\&O MPPT method [13]. Moreover, it adjusts the converter dc link voltage. In the literature, [25]-[26] the main focus on the cascade controller design of the converter. Here the non-linear system is converted to linearized using the small-signal model. It was having inner and outer loop controller. The inner loop controller response is faster than outer loop, moreover it has a drawback in behavior of converter inner loop controller. So, this problem can be overcome by choosing a new proposed technique for non-linear converter system which is using FBLC. Simulations are carried out for Constant Voltage Region (CVR), CCR and MPP region of the converter system. From the results it is found that, in the proposed method the converter system stability is improved for all the three cases. Furthermore, the proposed control technique is also performing well at different ambient conditions of the PV system.

\section{Photovoltaic-Converter Configuration:}

\subsection{Photovoltaic Modelling:}

The practical PV model can be represented by its equivalent circuit [4] as shown in Fig. 1, then the PV current $\left(\mathrm{I}_{\mathrm{pv}}\right)$ is given by:

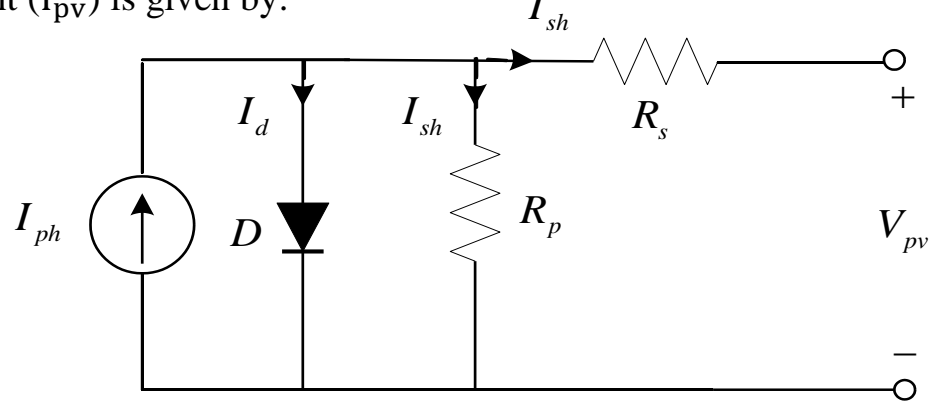

Fig 1. Equivalent model of PV Panel.

$$
I_{p v}=I_{p h}-I_{r s}\left(e^{\left(\frac{V_{p v}+I_{p v} R_{s}}{A}\right)}-1\right)-\left(\frac{V_{p v}+I_{p v} R_{s}}{R_{p}}\right)
$$

Where $\mathrm{I}_{\mathrm{ph}}$ the light current is directly proportional to the irradiance, $\mathrm{I}_{\mathrm{rs}}$ the diode reverse saturation current, $A=N_{s} * a * V_{t}, N_{s}$ the number of series connected $P V$ cells of the module, $V_{t}=k *$ 
$\mathrm{T} / \mathrm{q}, \mathrm{V}_{\mathrm{t}}$ the Thermal voltage, $\mathrm{T}$ is the temperature of the P-N junction in Kelvin's, a is the diode ideality factor and $q$ is the electron charge. $R_{s}$ and $R_{p}$ the series and shunt resistance respectively. The characteristics of PV module at Standard Test Conditions (STC) as shown in Fig. 2.

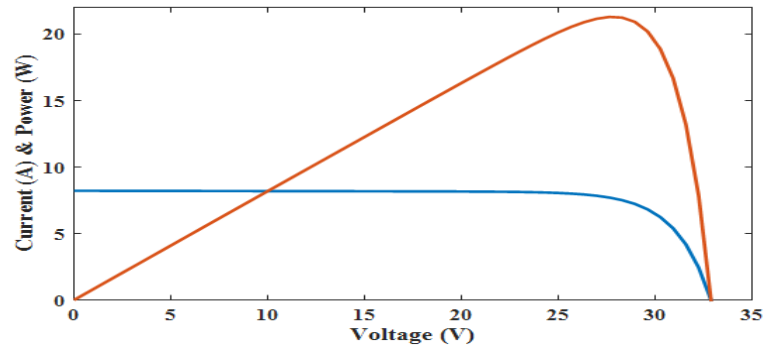

Fig 2. PV Characteristics STC.

The output voltage of DC-DC converer is maintained as constant for second stage conversion. The tracking can be done by using MPPT algorithm block diagram as shown in Fig.3, by monitoring the power at the terminals of the PV panel and regulated the voltage/current of the converter, compelling the PV array to operate at maximum power.

For this purpose P\&O MPPT algorithm have used due to simplicity of execution in the flowchart [13].From Eqn. (1), I-V characteristics exhibits non-linear relationship between voltage $\left(V_{p v}\right)$ and current $\left(I_{p v}\right)$ of panel. In order to obtain the linearized behaviour between $V_{p v} \& I_{p v}$. Thevenins voltage and its eqnivalent resistances are calculated and may be represented in the equivalent circuit of Fig. 4, where the thevenin's equivalent circuit as followed by Eqn. (2).
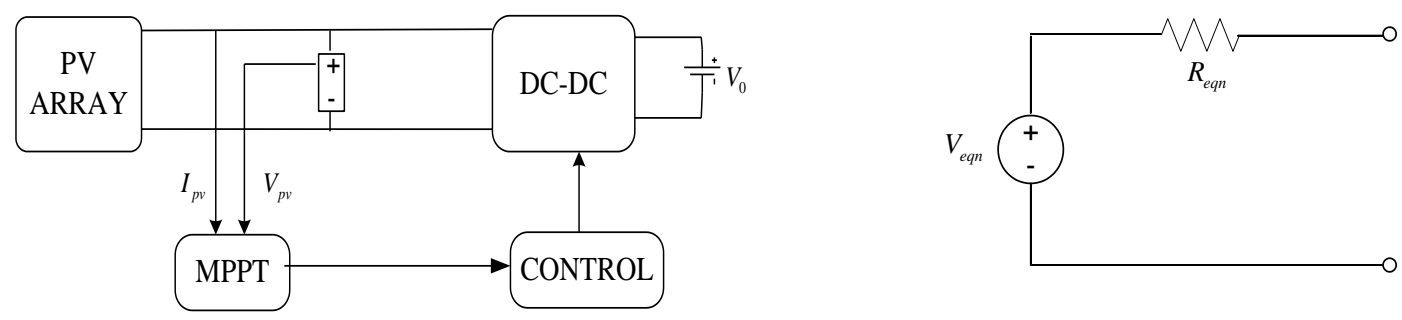

\section{Fig 3. Block Diagram for MPPT of DC-DC Converter. Fig 4. Linearized Circuit of a PV Panel.}

$$
\mathrm{V}_{\mathrm{EQ}}=\mathrm{V}_{\mathrm{pv}}-\frac{1}{\mathrm{~g}} \text { and } \quad \mathrm{r}_{\mathrm{EQ}}=-\frac{1}{\mathrm{~g}}
$$

Dynamic and static resistance curves are shown in Fig. 5, wherer $\mathrm{pv}_{\mathrm{pv}}=\mathrm{r}_{\mathrm{EQ}}$, is the dynamic resistance and $\mathrm{R}_{\mathrm{pv}}=\frac{\mathrm{V}}{\mathrm{I}}=\frac{1}{\mathrm{~g}}$, is the static resistance which further categorizes the behavior of PV source. It was based on the operating point location in the I-V curve divided into 3 regions. It is Seen from Fig. 2 and Fig. 5, in the CCR, wherer $\mathrm{pv}>\mathrm{R}_{\mathrm{pv}}$ at the MPP, $\mathrm{r}_{\mathrm{pv}}=\mathrm{R}_{\mathrm{pv}}$ lastly in the CVR, $\mathrm{r}_{\mathrm{pv}}<\mathrm{R}_{\mathrm{pv}}$. The $\mathrm{PV}$ panel specifications are presented in Table. I.

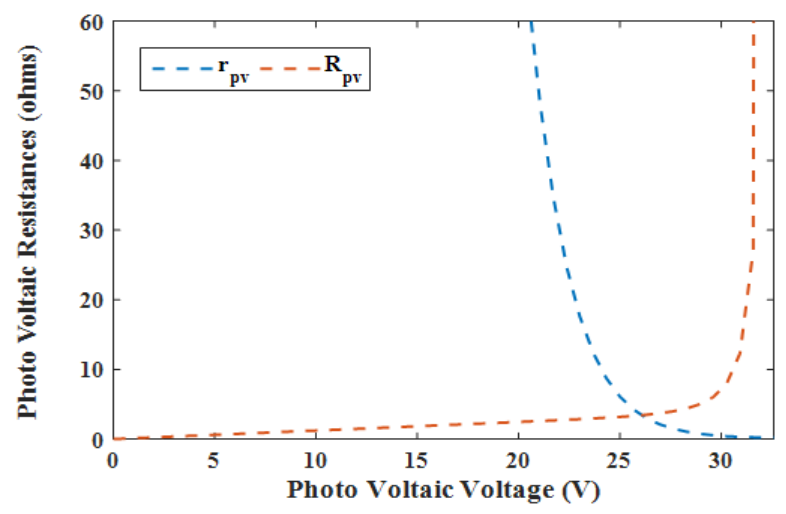

Fig 5. Dynamic and Static resistance curve. 
Table. I: Specifications of KC200GT PV Panel @STC

\begin{tabular}{|c|c|c|}
\hline \multicolumn{2}{|l|}{ Parameter } & Value \\
\hline \multicolumn{2}{|c|}{ Maximum Power $\left(\mathrm{P}_{\max }\right)$} & $200 \mathrm{~W}$ \\
\hline $\begin{array}{l}\text { Maximum } \\
\left(\mathrm{V}_{\mathrm{mpp}}\right)\end{array}$ & Voltage & $26.3 \mathrm{~V}$ \\
\hline $\begin{array}{l}\text { Maximum } \\
\left(\mathrm{I}_{\mathrm{mpp}}\right)\end{array}$ & Current & $7.61 \mathrm{~A}$ \\
\hline \multicolumn{2}{|c|}{ Open Circuit Voltage $\left(V_{o c}\right)$} & $32.9 \mathrm{~V}$ \\
\hline \multicolumn{2}{|c|}{ Short Circuit Current $\left(\mathrm{I}_{\mathrm{sc}}\right)$} & $8.21 \mathrm{~A}$ \\
\hline \multicolumn{2}{|c|}{ Number per cells Module } & 54 \\
\hline
\end{tabular}

\subsection{Boost Converter Modeling:}

The boost converter with input as $I_{p v}$, parasitic resistances of the inductor and capacitor as shown in Fig. 6. The control input $i_{p v}$ maintains the output of the converter Vo as constant by switching the MOSFET with the help of duty ratio obtained from the P\&O MPPT.

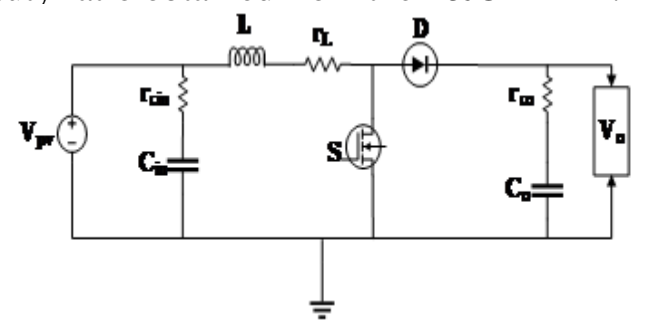

Fig 6. Modelling of Boost Converter.

The operation of converter can be illustrated by its switching conditions as shown in Fig. 7(a) \& Fig. 7(b), in order to obtain the linear model for state space representation in Eqn. (3). A linear average model of equations are considered for each switching operation as

$$
\begin{aligned}
& \dot{\mathrm{x}}=\mathrm{Ax}(\mathrm{t})+\mathrm{Bu}(\mathrm{t}) \\
& \mathrm{y}=\mathrm{Cx}(\mathrm{t})+\mathrm{Du}(\mathrm{t})
\end{aligned}
$$

$$
\text { Here } A=A_{1} d+A_{2}(1-d) ; B=B_{1} d+B_{2}(1-d)
$$

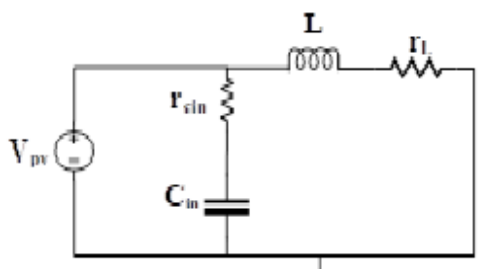

(a)

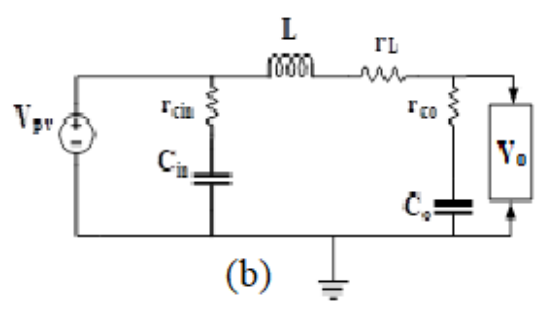

(b) $\stackrel{1}{=}$

Fig 7. Equivalent circuit during state (a) ON, (b) OFF.

During ON-state,

$$
\begin{aligned}
& \frac{d V_{\text {cin }}}{d t}=-i_{L}\left(\frac{r_{\text {cin }}}{C_{\text {in }} r_{\text {cin }}}\right)+i_{P V}\left(\frac{r_{\text {cin }}}{C_{\text {in }} r_{\text {cin }}}\right) \\
& \frac{d i_{L}}{d t}=\frac{V_{\text {cin }}}{L}-i_{L}\left(\frac{r_{\text {cin }}+r_{L}}{L}\right)+\frac{i_{P V} r_{\text {cin }}}{L}
\end{aligned}
$$

During OFF-state, 


$$
\begin{aligned}
& \frac{d V_{\text {cin }}}{d t}=-i_{L}\left(\frac{r_{\text {cin }}}{C_{\text {in }} r_{\text {cin }}}\right)+i_{P V}\left(\frac{r_{\text {cin }}}{C_{\text {in }} r_{\text {cin }}}\right) \\
& \frac{d i_{L}}{d t}=\frac{V_{\text {cin }}}{L}-i_{L}\left(\frac{r_{\text {cin }}+r_{L}}{L}\right)+\frac{i_{P V} r_{\text {cin }}}{L}
\end{aligned}
$$

Then overall switching cycle average state model is from Eqn. (4) \& Eqn. (5), as

$$
\left[\begin{array}{c}
\dot{V}_{\text {cin }} \\
i_{L}
\end{array}\right]=\left[\begin{array}{cc}
0 & \frac{-1}{C_{\text {in }}} \\
\frac{1}{L} & \frac{-\left(r_{\text {cin }}+r_{L}\right)}{L}
\end{array}\right]\left[\begin{array}{c}
\mathrm{V}_{\text {cin }} \\
\dot{i}_{\mathrm{L}}
\end{array}\right]+\left[\begin{array}{cc}
\frac{1}{\mathrm{C}_{\text {in }}} & 0 \\
\frac{\mathrm{r}_{\text {cin }}}{\mathrm{L}} & \frac{-(1-\mathrm{d})}{\mathrm{L}}
\end{array}\right]\left[\begin{array}{c}
\mathrm{i}_{\mathrm{PV}} \\
\mathrm{V}_{0}
\end{array}\right]
$$

\section{Control Strategy}

\subsection{Linear Cascade Control}

The overall average switching model of the converter system in Eqn. (6), controls the converter according to large signal stability which consists of both steady part and small-signal stability. In this control, the non-linear system can be linearized by performing perturbation and linearization at operating point, then linear small-signal state equation can be represented in the state space model $\dot{\hat{x}}=A \hat{x}+B u ̂$.

$$
\left[\begin{array}{c}
\dot{\hat{V}}_{c i n} \\
\dot{\hat{1}}_{\mathrm{L}}
\end{array}\right]=\left[\begin{array}{cc}
0 & \frac{-1}{\mathrm{C}_{\text {in }}} \\
\frac{1}{\mathrm{~L}} & \frac{-\left(\mathrm{r}_{\text {cin }}+\mathrm{r}_{\mathrm{L}}\right)}{\mathrm{L}}
\end{array}\right]\left[\begin{array}{c}
\hat{\mathrm{V}}_{\text {cin }} \\
\hat{\mathrm{i}}_{\mathrm{L}}
\end{array}\right]+\left[\begin{array}{ccc}
\frac{1}{\mathrm{C}_{\text {in }}} & 0 & 0 \\
\frac{\mathrm{r}_{\text {cin }}}{\mathrm{L}} & \frac{-(1-\mathrm{D})}{\mathrm{V}} \frac{\mathrm{V}_{0}}{\mathrm{~L}}
\end{array}\right]\left[\begin{array}{c}
\hat{\mathrm{i}}_{\mathrm{PV}} \\
\hat{\mathrm{V}}_{0} \\
\hat{\mathrm{d}}
\end{array}\right]
$$

In Eqn. (7), the values of $\mathrm{A}$ and $\mathrm{B}$ analogous to operating point, where $\hat{\mathrm{x}}=\left[\hat{\mathrm{V}}_{\operatorname{cin}} \hat{\mathrm{l}}_{\mathrm{L}}\right]^{\mathrm{T}}$ andû $=$ $\left[\hat{\mathrm{i}}_{\mathrm{pv}} \hat{\mathrm{V}}_{0} \hat{\mathrm{d}}\right]^{\mathrm{T}}$ are the state variables and inputs of the small signal model and $\hat{y}=\left[\hat{\mathrm{V}}_{\operatorname{cin}} \hat{\mathrm{l}}_{\mathrm{L}}\right]^{\mathrm{T}} \mathrm{is}$ the small signal output. The transfer function of the small signal model can be obtained by $\hat{y}(s)=[(\mathrm{SI}-$ $\left.A)^{-1} B\right] \hat{u}(s)$ which gives

$$
\left[\begin{array}{c}
\hat{V}_{\operatorname{cin}}(s) \\
\hat{l}_{L}(s)
\end{array}\right]=\left[\begin{array}{ccc}
G_{V_{\text {cin }} i_{p v}} & G_{V_{\text {cin }} V_{0}} G_{V_{\text {cin }} d} \\
G_{i_{L} i_{p v}} & G_{i_{L} V_{0}} & G_{i_{L} d}
\end{array}\right]\left[\begin{array}{c}
\hat{i}_{p v} \\
\hat{V}_{0} \\
\hat{d}
\end{array}\right]
$$

From Eqn. (8), the inner loop plant transfer function and outer loop plant transfer function, used in the design of linear cascade control are shown in Fig. 8, followed by Eqn. (9) \& Eqn. (10).

$$
\begin{gathered}
G_{i_{L} d}=\frac{\hat{\imath}_{L}}{\hat{d}}=\frac{\left(\frac{V_{0}}{L}\right) S}{S^{2}+\left(\frac{\left(r_{\operatorname{cin}}+r_{L}\right)}{L S+\left(\frac{1}{L C_{i n}}\right)}\right)} \\
G_{V_{\operatorname{cin}} i_{L}}=\frac{\frac{\hat{V}_{c i n}}{\hat{d}}}{\frac{\hat{l}_{L}}{\hat{d}}}=\frac{-1}{C_{\text {in }} S}
\end{gathered}
$$

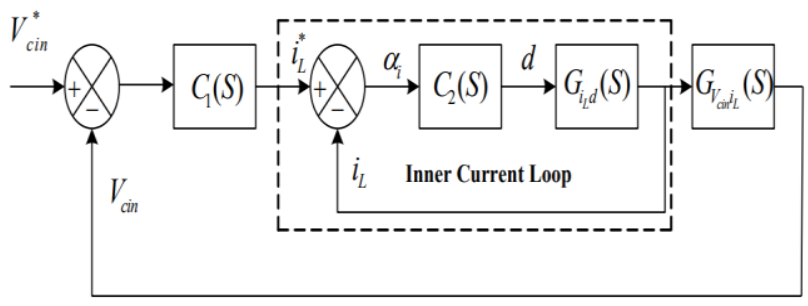

Fig 8. Linear Cascade Control. 


\subsection{Feedback Linearization Control}

Prior to analyzing the FBLC method in contrast to linear cascade controller, the FBLC laws are obtained from Eqn. (6). The non-linearity's appeared in Eqn. (6) is the cause of connection between the control inputs and the state variables in converter and by the non-linear term $\mathrm{I}_{\mathrm{pv}}$, which changes based on Eqn. (1). FBLC is a non-linear cascade controller developed with the help of input/output feedback linearization.

\subsubsection{Feedback Linearization Control:}

The inductor current dynamic equation from Eqn. (6) is,

$\frac{\mathrm{di}_{\mathrm{L}}}{\mathrm{dt}}=\frac{\mathrm{V}_{\text {cin }}}{\mathrm{L}}-\mathrm{i}_{\mathrm{L}}\left(\frac{\mathrm{r}_{\text {cin }}+\mathrm{r}_{\mathrm{L}}}{\mathrm{L}}\right)+\frac{\mathrm{i}_{\mathrm{PV}} \mathrm{r}_{\text {cin }}}{\mathrm{L}}-\frac{\mathrm{V}_{0}(1-\mathrm{d})}{\mathrm{L}}$

where the state variable can be treated as an $i_{L}$ and $V_{L}$ is a new control input of the inner loop, then the current through inductor can be written in the linearized model as

$\frac{\mathrm{di}_{\mathrm{L}}}{\mathrm{dt}}=\frac{\mathrm{V}_{\mathrm{L}}}{\mathrm{L}}$

We get linearized current controller $\mathrm{G}_{\mathrm{ci}}(\mathrm{s})$, with its output $\mathrm{v}_{\mathrm{L}}$ is applied to the new linear plant of transfer function $\frac{1}{\mathrm{LS}}$. Consider a proportional integral (PI) controller, then Eqn. (12) can be modified as

$$
\begin{aligned}
& \frac{\mathrm{di}_{\mathrm{L}}}{\mathrm{dt}}=\frac{1}{\mathrm{~L}}\left(\mathrm{~K}_{\mathrm{pi}}\left(\mathrm{i}_{\mathrm{L}}^{*}-\mathrm{i}_{\mathrm{L}}\right)+\mathrm{K}_{\mathrm{ii}} \alpha_{\mathrm{i}}\right) \\
& \frac{\mathrm{d} \alpha_{\mathrm{i}}}{\mathrm{dt}}=\left(\mathrm{i}_{\mathrm{L}}^{*}-\mathrm{i}_{\mathrm{L}}\right)
\end{aligned}
$$

Where $\alpha_{i}$ is the integrator output, but the actual control input ' $\mathrm{d}$ ' of the converter can be obtained by substitute Eqn. (13) into Eqn. (11), we get,

$$
\mathrm{d}=\frac{-\mathrm{V}_{\text {cin }}+\mathrm{i}_{\mathrm{L}}\left(\mathrm{r}_{\mathrm{cin}}+\mathrm{r}_{\mathrm{L}}\right)-\mathrm{i}_{\mathrm{pv}} \mathrm{r}_{\mathrm{cin}}+\mathrm{V}_{0}+\left(\mathrm{K}_{\mathrm{pi}}\left(\mathrm{i}_{\mathrm{L}}^{*}-\mathrm{i}_{\mathrm{L}}\right)+\mathrm{K}_{\mathrm{ii}} \alpha_{\mathrm{i}}\right)}{\mathrm{V}_{0}}
$$

is the inner loop current control law.

Generally, the bandwidth of inner loop is compares bandwidth of outer loop is very high, because of this reason compared to outer voltage loop, inner current loop reaches the actual value in quick manner, soi $i_{\mathrm{L}}^{*} \cong \mathrm{i}_{\mathrm{L}}$. Then the dynamics of the inductor current does not affect the outer voltage loop. Actually, wheni $\mathrm{L}_{\mathrm{L}}^{*} \cong \mathrm{i}_{\mathrm{L}}$, Eqn (15) gives $\mathrm{V}_{0}(1-\mathrm{d})=\mathrm{V}_{\text {cin }}-\mathrm{i}_{\mathrm{L}}\left(\mathrm{r}_{\text {cin }}+\mathrm{r}_{\mathrm{L}}\right)+\mathrm{i}_{\mathrm{pv}} \mathrm{r}_{\text {cin }}$, is placed in Eqn. (11) returns $\mathrm{i}_{\mathrm{L}} \cong 0$.

The capacitor voltage dynamic equation from Eqn. (6) is,

$$
\frac{\mathrm{dV}_{\mathrm{cin}}}{\mathrm{dt}} \cong \frac{-\mathrm{i}_{\mathrm{L}}^{*}}{\mathrm{C}_{\mathrm{in}}}+\frac{\mathrm{i}_{\mathrm{pv}}}{\mathrm{C}_{\mathrm{in}}}
$$

Where $\mathrm{i}_{\mathrm{L}}^{*}$ is the control input of the outer voltage loop and $\mathrm{V}_{\text {cin }}$ is the state variable. The linearized average value of the capacitor voltage can be obtained by taking new control input $i_{\text {cin }}$ (rather thani* $\mathrm{L}_{\mathrm{L}}^{*}$, is

$$
\frac{\mathrm{dV}_{\text {cin }}}{\mathrm{dt}}=\frac{\mathrm{i}_{\text {cin }}}{\mathrm{C}_{\text {in }}}
$$

We get linear current controller $G_{\text {cin }}(S)$, whose output is $i_{\text {cin }}$ applied to the new linear plant of transfer function $\frac{1}{\mathrm{C}_{\mathrm{in}} \mathrm{S}}$. Consider a proportional integral (PI) controller, then Eqn. (17) can be modified as

$$
\begin{aligned}
& \frac{d V_{\text {cin }}}{d t}=\frac{1}{C_{\text {in }}}\left(K_{p v}\left(V_{\text {cin }}^{*}-V_{\text {cin }}\right)+K_{i v} \alpha_{v}\right) \\
& \frac{d \alpha_{v}}{d t}=\left(V_{\text {cin }}^{*}-V_{\text {cin }}\right)
\end{aligned}
$$

Where $\alpha_{v}$ is the integrator output, but the actual control input $i_{L}^{*}$ of the converter can be obtained by substitute Eqn. (18) into Eqn. (16). 
If substitute the Eqn. (20) in Eqn. (16), which cancels the non-linearity produced by the term $\mathrm{i}_{\mathrm{pv}}$.

$$
\mathrm{i}_{\mathrm{L}}^{*}=\mathrm{i}_{\mathrm{pv}}-\left(\mathrm{K}_{\mathrm{pv}}\left(\mathrm{V}_{\text {cin }}^{*}-\mathrm{V}_{\text {cin }}\right)+\mathrm{K}_{\mathrm{iv}} \alpha_{\mathrm{v}}\right)
$$

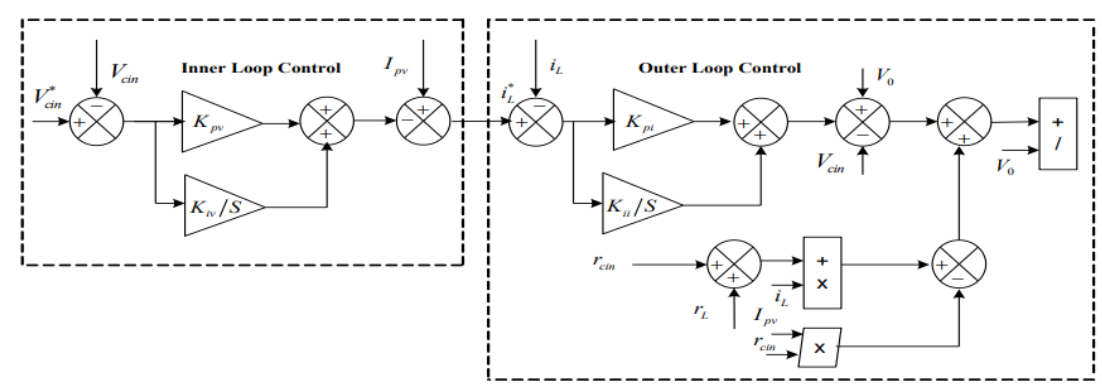

Fig 9. Controller design of Feedback Linearization

\section{Result Analysis}

In this section, the results of simulation are delivered to validate the successful of the proposed controller on boost converter. A $200 \mathrm{~W}$ boost converter is designed with the help of parameters mentioned in Table. I and Table. II. First, the behaviour of the converter system is analysed for uncertainties in gain parameters and stability of converter system by applying cascade control technique. Later, the proposed controller is also analysed for uncertainties in control parameters, different irradiance and different temperature conditions. The FBLC technique is used to test the output of the converter under this condition using MATLAB/Simulink software.

\subsection{Cascade Control}

A linear cascade controller was developed with the Eqn. (9) \& Eqn. (10). From the block diagram as shown in Fig. 8, The conventional controllers have with outer loop and inner loop, which are used to control the input capacitor voltage and average inductor current respectively. The controller is evaluated by changing the proportional gain of the outer loop controller. During simulation, a constant voltage is maintained to the converter at the STC.

Table. II: Converter Parameters.

\begin{tabular}{ll}
\hline Parameter & Value \\
\hline Inductor & $48.15 \mu \mathrm{H}$ \\
Capacitor & $40 \mu \mathrm{F}$ \\
Input Resistance & $3 \mathrm{~m} \Omega$ \\
Output Resistance & $3 \mathrm{~m} \Omega$ \\
Load Resistance & $8.9 \mathrm{~m} \Omega$ \\
\hline
\end{tabular}

\subsubsection{Uncontrolled/Controlled Study of Cascade Controller:}

The output of the converter system for uncontrolled case can be seen in Fig. 10. The input capacitor voltage value reached a peak value of $31.7 \mathrm{~V}$ and settled at $0.3 \mathrm{msec}$ without any oscillatory behavior and the average inductor current was not reached to steady value in uncontrolled case indicates the blue line. In order to considering controlled case as shown in Fig. 10 represents the response of the input capacitor voltage of $32.7 \mathrm{~V}$ is settled at $2 \mathrm{msec}$ and the Inductor current still not reached steady value to the specified values of the gain controller in Table. III.

\section{Table. III: Converter Parameters.}

\begin{tabular}{lcc}
\hline Gain & $\begin{array}{l}\text { Outer } \\
\text { Loop }\end{array}$ & $\begin{array}{l}\text { Inner } \\
\text { Loop }\end{array}$ \\
\hline Proportional & 0.4 & 45 \\
Integral & 0.1 & 0.01 \\
\hline
\end{tabular}




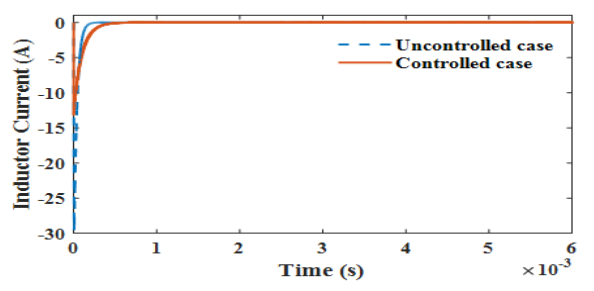

(a)

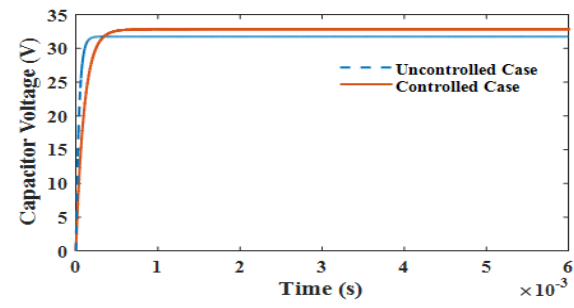

(b)

\section{Fig 10. Uncontrolled and Controlled cases (a) Inductor Current (b) Capacitor Voltage.}

\subsubsection{Considering Uncertainties in Control Parameters:}

The output of the converter control system has considering uncertainties in the control parameters as like $25 \%, 50 \%$ and $75 \%$ in Fig. 11 . While $V_{\text {cin }}$ reaches a value of $32.7 \mathrm{~V}$ with steady state value at $2 \mathrm{msec}, 1 \mathrm{msec}$ and $0.9 \mathrm{~m} \mathrm{sec}$.For the different changed gain values of the cascaded control analysis of the inductor current responses not much significant value is represented in Fig. 11(a). The proportional gain of the outer loop controller was set to different uncertainties of its actual value as shown in Fig. 11(b). From these, the maximum value of the input capacitor voltage was obtained by introducing a control parameter compare to uncontrolled system, although this increases the system settling time, resulting in decreased stability. The response to different irradiance $(\mathrm{G})$ and temperature (T) conditions of the Fig. 13. Transfer Function of Inductor Current to Capacitor Voltage and inductor current was also observed, but due to the linearization of the parameters, they had almost no effect.
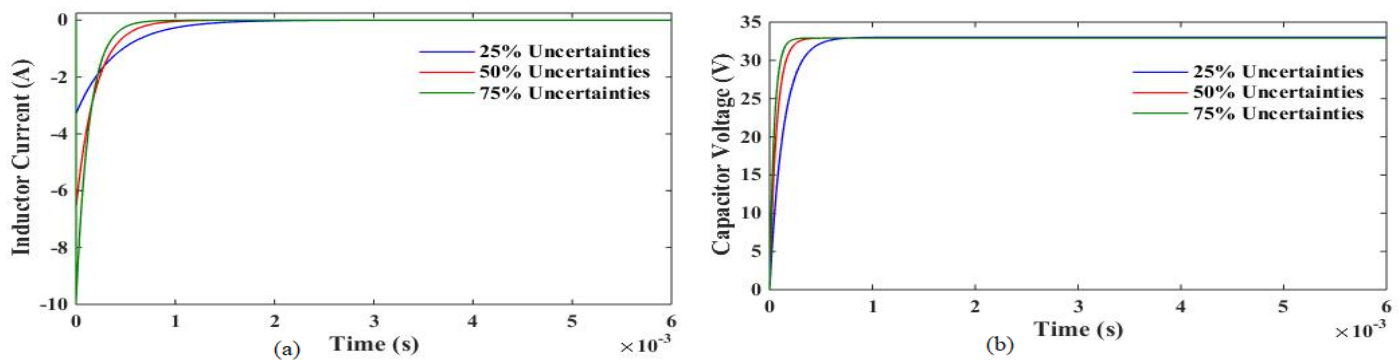

Fig 11. Uncertainties in control parameter variations (a) Inductor Current. (b) Capacitor Voltage.

\subsubsection{Stability Analysis of Converter System Operating Regions:}

Fig. 12 shows the ratio of duty cycle to inductor current transfer function for the three operating regions of I-V curve as mentioned in Table. IV. Blue, Red, Green line indicates the response of transfer function operating at CCR, MPP, CVR regions. In the current source region, from Fig.5, the value of equivalent resistance $R_{\text {eqn }}$ is very high which results in poor controllability of the inductor current due to the negative value of DC gain. Fig. 13 indicates the inductor current to input voltage transfer function for the three operating regions of I-V curve. In CVR, from Fig. 5, the value of equivalent resistance $R_{\text {eqn }}$ is low. This leads to a low value of DC gain, due to which variations in the inductor current have a small effect in the input voltage of the converter.

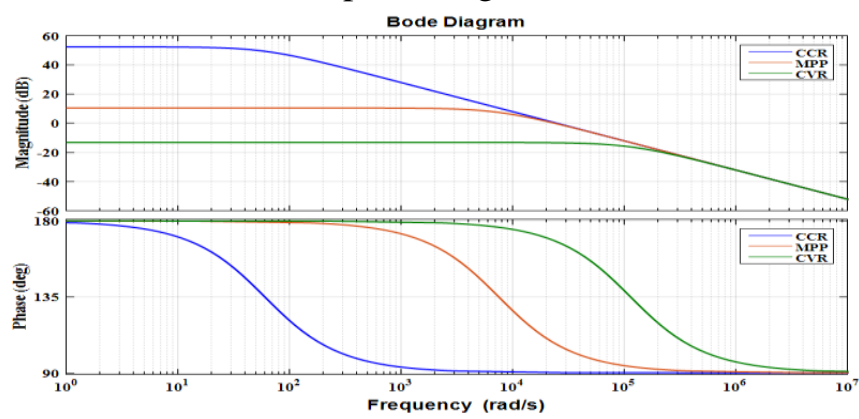

Fig 12. Transfer Function $\left(\mathrm{G}_{\mathrm{iLD}}\right)$ Duty to Current through Inductor 


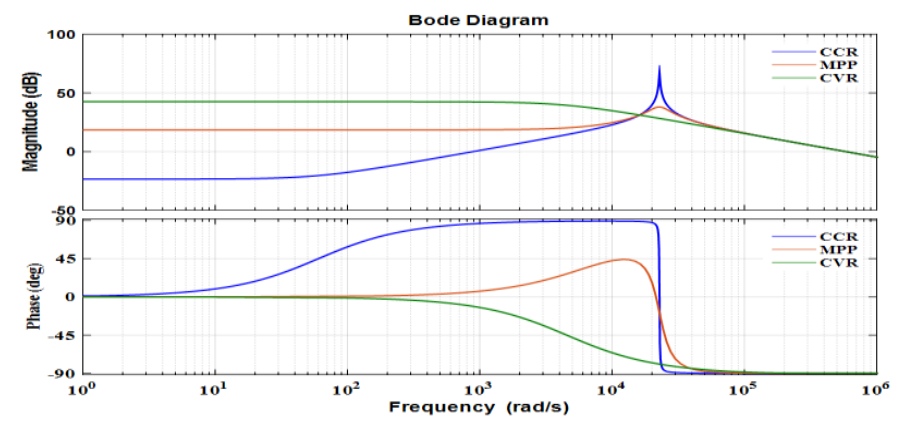

Fig 13. Transfer Function of Inductor Current to Capacitor Voltage.

Table. IV: Equivalent Voltage and Resistance of Linearized PV Curve

\begin{tabular}{ccc}
\hline Region & $\mathrm{V}_{\text {eqn }}(\mathrm{V})$ & $\mathrm{R}_{\text {eqn }}(\Omega)$ \\
\hline CCR & 3412 & 415.37 \\
MPR & 51.635 & 3.329 \\
CVR & 32.9 & 0.2195
\end{tabular}

\subsection{Feedback linearization Control}

The proposed controller has been developed with the help of Eqn. (13) - Eqn. (15) and Eqn.(18) Eqn.(20). From the diagram shown in Fig. 9, where the inner loop controls the average value of the inductor current with control parameters while the outer loop controls the voltage of the input capacitor, with voltage control parameters. The controller is assessed by varying the outer loop voltage controller proportional gain in Table. V. A constant voltage load, set to $28 \mathrm{~V}$ and PV at STC along with different irradiances and ambient temperature is applied to the converter during the test cycle.

\begin{tabular}{|c|c|c|}
\hline Gain & $\begin{array}{l}\text { Outer } \\
\text { Loop }\end{array}$ & $\begin{array}{l}\text { Inner } \\
\text { Loop }\end{array}$ \\
\hline Proportional & 1.2 & 530 \\
\hline Integral & 0.9 & 0.87 \\
\hline
\end{tabular}

\subsubsection{Uncontrolled/Controlled Study of Feedback Linearization:}

In Fig. 14 depicts the response of a converter system with and without controller. Here the voltage of the input capacitor and average inductor current reaches to the steady state value $32.9 \mathrm{~V}, 8.21 \mathrm{~A}$ at $0.7 \mathrm{msec}$ and $0.6 \mathrm{~m} \mathrm{sec}$ respectively in uncontrolled case indicates the red line. The responses of input capacitor voltage and inductor current with the specified values of the controller gains are depicted in Fig. 14. Where $\mathrm{V}_{\text {cin }}$ reaches to a value of $32.9 \mathrm{~V}$ at $0.7 \mathrm{msec}, \mathrm{i}_{\mathrm{L}}$ value is reached to steady state value $8.21 \mathrm{~A}$ with a settling time of $0.6 \mathrm{msec}$ without any oscillator behavior.

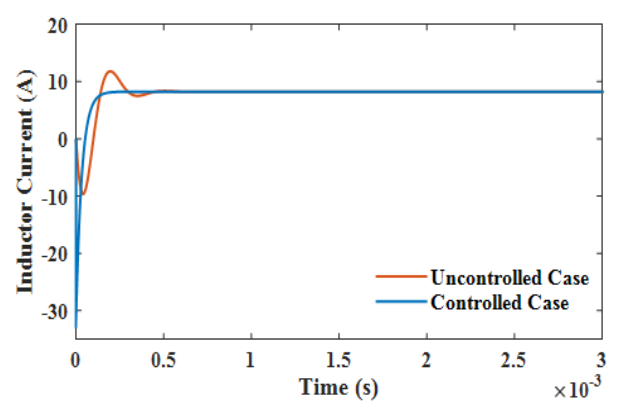

(a)

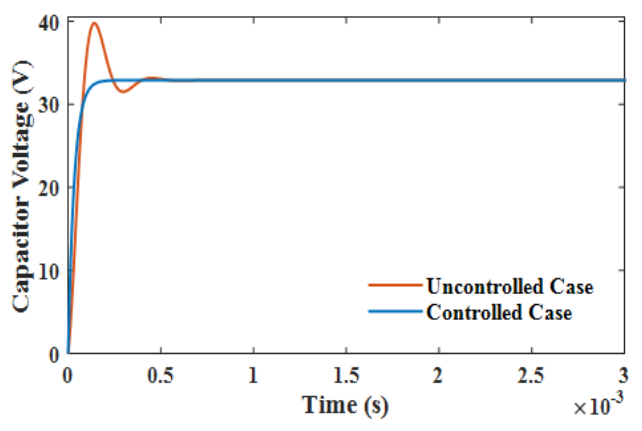

(b)

Fig 14. Uncontrolled and Controlled Case study of FBLC (a) Inductor Current. (b) Capacitor Voltage. 


\subsubsection{Considering Uncertainties in Control Parameters:}

The proportional gain parameter of the outer loop considered in $25 \%, 50 \%$ and $75 \%$ uncertainties in the actual value respectively in Fig. 15 (a) \& Fig. 15 (b), then $\mathrm{V}_{\text {cin }}, i_{\mathrm{L}}$ hits $32.9 \mathrm{~V}$ with a settling time of $0.7 \mathrm{msec}, 0.4 \mathrm{msec}$ and $0.3 \mathrm{msec}$ respectively and $8.21 \mathrm{~A}$ at $0.6 \mathrm{msec}, 0.4 \mathrm{msec}$ and $0.3 \mathrm{msec}$ to reaches a steady state value.
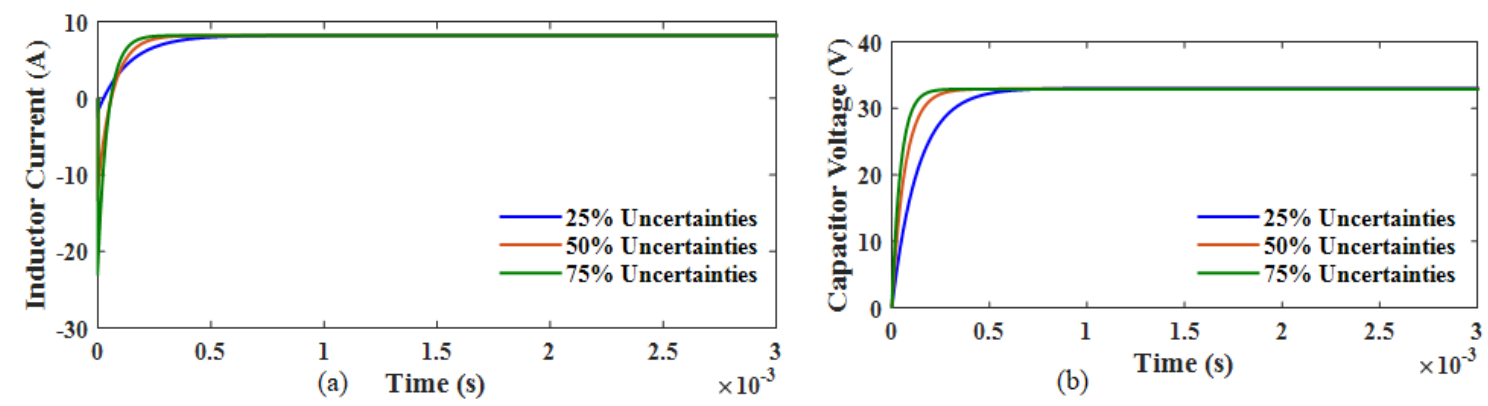

\section{Fig 15. Uncertainties in control parameter variations in FBLC (a) Inductor Current. (b) Capacitor Voltage.}

\subsubsection{Comparison of Cascade and Feedback Linearization:}

The comparison of cascade and feedback linearization response is represented in Fig. 16. Here, the performance of both inductor current as well as capacitor voltage gives better response in settling time is less, inductor current reaches the steady state value and voltage is almost constant as mentioned in Table. VI.
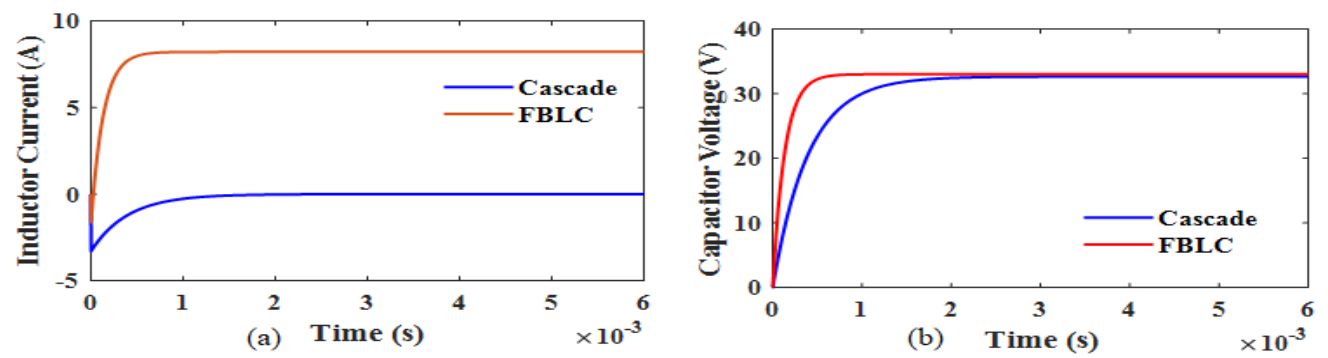

Fig 16. Simulation results for Comparison of Cascade and Feedback Linearization (a) Inductor Current. (b) Capacitor Voltage.

Table. VI. Comparison of Cascade and Feedback Linearization

\begin{tabular}{c|c|c|c|c}
\hline \multirow{2}{*}{ Control } & \multicolumn{2}{|c|}{ Magnitudes } & \multicolumn{2}{c}{ Settling Time } \\
\cline { 2 - 5 } & $\mathrm{i}_{\mathrm{L}}(\mathrm{A})$ & $\mathrm{V}_{\mathrm{c}}(\mathrm{V})$ & $\mathrm{i}_{\mathrm{L}}$ & $\mathrm{V}_{\mathrm{c}}$ \\
\hline Cascade & 0 & 32.7 & $1 \mathrm{~m} \mathrm{sec}$ & $2 \mathrm{~m} \mathrm{sec}$ \\
FBLC & 8.21 & 32.9 & $0.6 \mathrm{~m} \mathrm{sec}$ & $0.7 \mathrm{msec}$ \\
\hline
\end{tabular}

\subsubsection{Different irradiation and temperatures conditions:}

The inductor current response can be analyzed by applying different irradiance and temperature conditions. Here, inductor current is varied in significant manner for changing in irradiance in Fig. 17 (a). In climatic conditions, the magnitude of inductor current in Fig. 17 (b). In both cases capacitor voltage was unchanged. 

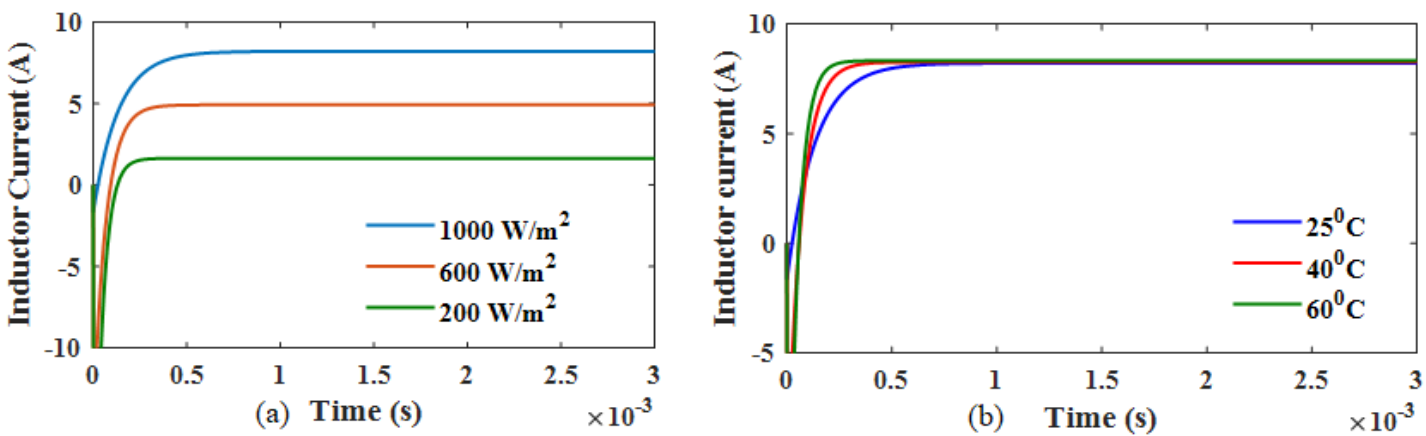

\section{Fig 17. Simulation Results of Different irradiance and temperature conditions (a) Inductor Current. (b) Capacitor Voltage.}

\section{Conclusion}

A non-inverting converter with control input voltage for PV applications was designed and tested by applying the FBLC technique. The weaknesses of linear cascade control scheme were discussed as earlier. The equivalent resistance $R_{e q n}$ of CCR region was very high, due to this high value of resistance it leads to negative value of dc gain and the inductor current response was also very poor. So, that the FBLC technique overcome these issues and also improve the stability of the converter which are highly affected on control gain parameters. Moreover, the proposed technique inductor current and capacitor voltage responses reach steady state in quick manner and also settling time was reduced. The input voltage is selected to be the control variable because it presents small variations with changes in irradiance and temperatures also observed. So, we conclude the stability of the converter system behavior was improved and also the proposed control law cancels the system nonlinearity.

\section{References}

[1] Kabir.E,Kumar.P,Kumar.S,AdelodunA.A., KimK.H. "Solar energy: Potential and future prospects” Renew. Sustain. Energy, Rev. 2018, 82, 894-900.

[2] Venkata R. Vakacharlaa, K. Gnanab, P. Xueweic, B.L. Narasimaharajud, ManguBhukyae, AtanuBanerjeef, RenuSharmag, Akshay K. Rathorea "State-of-the-art power electronics systems for solar-to-grid integration", Solar Energy 210 (2020) 128-148.

[3] Azzouzi, M., 2014. Modeling and simulation of a photovoltaic cell considering singlediode model. In: Lepadatescu, B., Borne, P., Batzias, F. (Eds.), Recent Advances inEnvironmental Science and Biomedicine. WSEAS Press, North Atlantic UniversityUnion, pp. 175-182.

[4] Vinod; Kumar, R.; Singh, S.K. Solar photovoltaic modeling and simulation: As a renewable energy solution. Energy 2018, 4,701-712.

[5] Simulation, validation and analysis of shading effects on a PV system, Sara GallardoSaavedra, Björn Karlsson, Solar Energy 170 (2018) 828-839.

[6] HamzaMokhliss, Khalid Rais, Asseya El-Amiri, Bounouar, et.al, "An accurate method for parameters determination ofcurrent voltage characteristics of photovoltaic modules" IEEE/ICCSRE2019, 22-24 July, 2019.

[7] SuneelRajuPendem, Suresh Mikkili," Modelling and performance assessment of PV array topologies under partial shading conditions to mitigate the mismatching power losses", Solar Energy 160 (2018) 303-321.

[8] BidyadharSubudhi, Senior Member, IEEE, and Raseswari Pradhan "A Comparative Study on Maximum Power Point Tracking Techniques for Photovoltaic Power Systems" IEEE Transactions on sustainable energy, vol. 4, no. 1, January 2013.

[9] Bendib, Boualem, HocineBelmili, and Fateh Krim. "A survey of the most used MPPT methods: Conventional and advanced algorithms applied for photovoltaic systems." Renewable and Sustainable Energy Reviews 45 (2015): 637-648. [10] Fangrui Liu, ShanxuDuan, Fei Liu, Bangyin Liu, and Yong Kang "A Variable Step Size INC MPPT Method for PV Systems", IEEE transactions on industrial electronics, vol. 55, no. 7, July 2008.

[11] AfshanIlyas, Mohammad Ayyub, et.al "Realization of Incremental Conductance MPPTAlgorithm for Solar Photovoltaic System”, International Journal of Ambient Energy, Taylor \& Francis Group, 2017.

[12] Ali, Ahmed IM, Mahmoud A. Sayed, and Essam EM Mohamed. "Modified efficient perturb and observe maximum power point tracking technique for grid-tied PV system." International Journal of Electrical Power \& Energy Systems 99 (2018): 192-202.

[13] KollimallaSathish Kumar, Mishra Mahesh K. Variable perturbation size adaptive $p$ \& o mppt algorithm for sudden changes in irradiance. Sustain Energy, IEEE Trans 2014;5(3):718-28.

[14] Hossain, M. Z., and N. A. Rahim. "Recent progress and development on power DC-DC converter topology, control, design and applications: A review." Renewable and Sustainable Energy Reviews 81 (2018): 205-230.

[15] A. J. Forsyth and S. V. Mollov, "Modelling and control of DC-DC converters", Power Engineering Journal October, 1998- IET. 
[16] Cheng-Wei Chen, Kun-Hung Chen, and Yaow-Ming Chen, "Modeling and Controller Design of an Autonomous PV Module for DMPPT PV Systems", IEEE transactions on power electronics, vol. 29, no. 9, September 2014.

[17] SébastienMariéthoz, Stefan Almér et.al "Comparison of Hybrid Control Techniques for Buckand Boost DC-DC Converters" IEEE transactions on control systems technology, vol. 18, no. 5, September 2010.

[18] Shiau, Jaw-Kuen, Min-Yi Lee, Yu-Chen Wei, and Bo-Chih Chen. "Circuit simulation for solar power maximum power point tracking with different buck-boost converter topologies." Energies 7, no. 8 (2014): 5027-5046.

[19] Weidong Xiao, William G. Dunford, Patrick R. Palmer and Antoine Capel "Regulation of Photovoltaic Voltage" IEEE transactions on industrial electronics, vol. 54, no. 3, June 2007.

[20] Sun, Jian, Daniel M. Mitchell, Matthew F. Greuel, Philip T. Krein, and Richard M. Bass. "Averaged modeling of PWM converters operating in discontinuous conduction mode." IEEE Transactions on power electronics 16, no. 4 (2001): 482-492.

[21] R. D. Middlebrook, "Small-Signal Modelling of Pulse-Width Modulated Switched-Mode Power Converters", proceedings of the IEEE, vol. 76, no. 4, April 1988.

[22] Alvarez-Ramirez, Jose, Ilse Cervantes, Gerardo Espinosa-Perez, Paul Maya, and America Morales. "A stable design of PI control for DC-DC converters with an RHS zero." IEEE Transactions on Circuits and Systems I: Fundamental Theory and Applications 48, no. 1 (2001): 103-106.

[23] Perry, Alexander G., Guang Feng, Yan-Fei Liu, and Paresh C. Sen. "A design method for PI-like fuzzy logic controllers for DC-DC converter." IEEE transactions on industrial electronics 54, no. 5 (2007): 2688-2696.

[24] Stefanutti, Walter, Paolo Mattavelli, Stefano Saggini, and Massimo Ghioni. "Autotuning of digitally controlled DCDC converters based on relay feedback." IEEE transactions on power electronics 22, no. 1 (2007): 199-207.

[25] Bellinaso, Lucas Vizzotto, Henrique Horst Figueira, Mauro Fernando Basquera, Rodrigo Padilha Vieira, Hilton AbílioGründling, and Leandro Michels. "Cascade control with adaptive voltage controller applied to photovoltaic boost converters." IEEE Transactions on Industry Applications 55, no. 2 (2018): 1903-1912.

[26] Badis, Afef, Mohamed Nejib Mansouri, and Mohamed Habib Boujmil. "Cascade control of grid-connected pv systems using tlbo-based fractional-order pid." International Journal of Photoenergy 2019 (2019).

[27] Toodeji, Hamidreza, and Shahram Aghaei. "Domestic PV System with Feedback Linearization-Based Control Strategy for Module-Level MPPT under Partial Shading Condition." Journal of Modern Power Systems and Clean Energy (2020).

[28] Sharma, Rahul, and Sathans Suhag. "Feedback linearization-based control for weak grid connected PV system under normal and abnormal conditions." Frontiers in Energy 14, no. 2 (2020): 400-409. 